\title{
Behavioral Evidence of Depolarization Block of Dopamine Neurons after Chronic Treatment with Haloperidol and Clozapine
}

\author{
Sandra M. Boye ${ }^{1}$ and Pierre-Paul Rompré 1,2 \\ ${ }_{1}^{1}$ Center for Studies in Behavioral Neurobiology, Concordia University, Montreal, Québec, Canada, H3G 1M8, \\ and 'Centre de Recherche de l'Hôpital du Sacré-Coeur et Département de Psychiatrie, Université de Montréal, \\ Montréal, Québec, Canada, H3C 3J7
}

\begin{abstract}
Electrophysiological studies have shown that chronic treatment with haloperidol causes depolarization block (DB) of dopamine cells in anesthetized and paralyzed rats. It has been proposed that the emergence of DB underlies the therapeutic and side effects of this drug. However, the relevance of DB to the clinical actions of haloperidol has been questioned on the grounds that chronic drug-induced DB has not yet been demonstrated in freely moving animals. In this study, responding for rewarding electrical brain stimulation was used to assess the occurrence of $\mathrm{DB}$ in rats chronically treated with haloperidol or clozapine. The time course of the effects of acute haloperidol (7.8-500 $\mu \mathrm{g} / \mathrm{kg}$ ) and clozapine $(5-40 \mathrm{mg} / \mathrm{kg}$ ) and of withdrawal from chronic drug treatment on reward and performance measures were also characterized. Haloperidol and clozapine dosedependently attenuated reward and performance, haloperidol producing a predominant suppression of performance, and clozapine preferentially attenuating reward. Chronic (21 d) treatment with haloperidol $(500 \mu \mathrm{g} / \mathrm{kg}$ ) caused responding to cease
\end{abstract}

in the six rats tested, and repeated injection with apomorphine restored the behavior in all of them; such an effect of apomorphine was observed in only two of six rats treated acutely with the same dose of haloperidol. Chronic treatment with clozapine (20 mg/kg) increased reward thresholds, an effect that was reversed by apomorphine in chronically, but not acutely, treated rats. The times at which chronic haloperidol-treated rats resumed responding was positively correlated with indices of behavioral supersensitivity after withdrawal, suggesting that the effect of apomorphine was not caused by direct stimulation of upregulated postsynaptic receptors. These findings constitute the first behavioral evidence of DB in unanesthetized, freely moving animals treated chronically with antipsychotics. They also demonstrate that the neural substrates mediating reward and performance are functionally independent and differentially sensitive to haloperidol and clozapine.

Key words: apomorphine; behavioral supersensitivity; clozapine; depolarization block; dopamine; haloperidol; reward
Acutely, classical antipsychotics are potent stimulants of midbrain dopamine (DA) cell firing. Chronically, however, classical antipsychotics produce complete cessation of firing activity in a majority of midbrain DA cells (Bunney and Grace, 1978), a phenomenon resulting from sustained depolarization of the membrane potential as a consequence of prolonged excitation (Grace and Bunney, 1986); firing activity in these cells can be reinstated after repolarization of the membrane potential. Repeated treatment with atypical antipsychotics also produces depolarization block (DB) of midbrain DA cells. However, although both classical and atypical antipsychotics inactivate mesolimbic (A10) DA cells, only the former additionally inactivate nigrostriatal (A9) DA cells (Chiodo and Bunney, 1983; White and Wang, 1983b; Skarsfeldt, 1988). It has been proposed that DB of A10 and A9 DA cells may contribute, respectively, to the therapeutic effect and extrapyramidal syndromes associated with classical antipsychotics (e.g., haloperidol), whereas the selective inactivation of A10 DA cells may reflect the reduced propensity for extrapyra-

\footnotetext{
Received July 8, 1999; revised Nov. 9, 1999; accepted Nov. 9, 1999.

This work was supported by a grant from the Medical Research Council of Canada to P.-P.R. Clozapine was a generous gift from Sandoz (Dorval, Québec, Canada).

Correspondence should be addressed to P.-P. Rompré at his present address: Centre de Recherche Fernand-Seguin, Hôpital Louis-H. Lafontaine, 7331 Hochelaga, Montréal, Québec, Canada, H1N 3V2. E-mail: prompre@crfs.umontreal.ca.

Dr. Boye's present address: Department of Pharmacology and Therapeutics, McGill University, Montréal, Québec, Canada, H3G 1Y6.

Copyright (C) 2000 Society for Neuroscience $0270-6474 / 00 / 201229-11 \$ 15.00 / 0$
}

midal syndromes associated with atypical antipsychotics (e.g., clozapine) (for review, see Grace et al., 1997).

Two behavioral studies have provided findings consistent with induction of DB of midbrain DA cells. In both, responding for rewarding electrical brain stimulation (EBS) ceased after acute neuroleptic treatment combined with either morphine (Rompré and Wise, 1989) or a partial DA lesion (Doherty and Gratton, 1991). That the absence of responding was attributable to DB is supported by the finding that, in both studies, responding was restored with drugs that normally hyperpolarize DA cells. In a third study, acute neuroleptic challenge produced greater catalepsy and akinesia in rats with partial DA lesions than in controls, a difference attributed to induction of DB (Hollerman et al., 1992). To date, it has not been demonstrated that chronic exposure to antipsychotic drugs leads to DB in intact, freely moving animals. Moreover, although early electrophysiological studies performed on unanesthetized rats have provided evidence of DB after repeated exposure to antipsychotic drugs (Bunney and Grace, 1978; Chiodo and Bunney, 1985), two recent studies have failed to replicate this finding (Mereu et al., 1994, 1995; Melis et al., 1998). These inconsistent findings and the lack of behavioral data from chronically treated animals have led some to propose that DB results from the combined influence of anesthesia and the stimulatory effects of haloperidol and the sampling procedure (Mereu et al., 1994, 1995; Melis et al., 1998).

The primary purpose of this study was to test the hypothesis that chronic treatment with haloperidol leads to the development 
of DB in freely moving animals responding for rewarding EBS. This behavioral paradigm was chosen because it is sensitive to manipulations of central dopamine neurotransmission (Gallistel and Karras, 1984; Gallistel and Freyd, 1987; Rompré and Wise, 1989), and it has been used previously to infer DB of DA cells (Rompré and Wise, 1989; Doherty and Gratton, 1991). For comparison, the effects of chronic treatment with clozapine were also studied. To better understand the results of the DB test, the effects of acute and postwithdrawal haloperidol and clozapine on reward and performance were also characterized.

\section{MATERIALS AND METHODS}

Subjects. Subjects were male Long-Evans rats weighing between 350 and $450 \mathrm{gm}$ at the time of surgery. Each rat was individually housed, had access to food and water ad libitum, and was maintained on a 14/10 hr light/dark cycle (lights off at 5:30 P.M.). Behavioral testing was performed during the light phase.

Surgery. Twenty minutes before surgery, rats were treated with atropine sulfate $(0.5 \mathrm{mg} / \mathrm{kg})$ to reduce mucous secretion. Under sodium pentobarbital anesthesia (Somnotol, $65 \mathrm{mg} / \mathrm{kg}$, i.p.), animals were stereotaxically implanted with a moveable stimulation electrode (Kinetrods, SME-01) aimed at the medial mesencephalic central gray using the following flat skull coordinates: $7.6 \mathrm{~mm}$ behind bregma, $0.0 \mathrm{~mm}$ lateral to bregma, and $6.6 \mathrm{~mm}$ below the skull (Paxinos and Watson, 1986). A flexible wire connected at one end to a male amphenol pin and wrapped around six stainless steel mounting screws that were threaded into the cranium served as the inactive electrode (anode). Acrylic dental cement was used to chronically secure the electrode assembly to the skull.

Apparatus. Behavioral testing was performed in operant chambers made from plywood and Plexiglas. Each chamber was equipped with a lever (Lehigh Valley, Allentown, PA) that protruded from the left wall, $5 \mathrm{~cm}$ above the wire-mesh floor. To minimize disturbances caused by noise, chambers were encased in wooden boxes insulated with Styrofoam; a Plexiglas front window allowed constant viewing of the rat.

Each depression of the lever triggered a constant-current generator to deliver a single $200 \mathrm{msec}$ train of $0.1 \mathrm{msec}$ cathodal rectangular pulses. Each stimulation train was followed by an $800 \mathrm{msec}$ intertrain interval during which stimulation was not available (Boye and Rompré, 1996). Current intensity was monitored on an oscilloscope by reading the voltage drop across a $1 \mathrm{~K} \Omega$ resistor in series with the rat.

Behavioral training. Forty-eight to $72 \mathrm{hr}$ after surgery, animals were trained to lever press for stimulation of the mesencephalic central gray region using conventional shaping procedures. If the stimulation induced aversive reactions or did not support lever pressing, the electrode was lowered by $0.32 \mathrm{~mm}$ and the next site was tested; generally, lowering the electrode once was sufficient. Once the lever-pressing response was established, rats were allowed to lever press continuously for $1 \mathrm{hr}$ at stimulation parameters set to support vigorous responding. Rats were then tested during sessions in which the stimulation current intensity was held constant and the number of pulses per train was systematically reduced. A "pass" consisted of testing a descending series of pulse numbers, in $\sim 0.1 \log$ unit steps, ranging from a value that sustained maximal response rates ( 31 pulses per train, $155 \mathrm{~Hz}$ ) to a value that failed to sustain responding (two pulses per train, $10 \mathrm{~Hz}$ ). To ensure that the rat was within proximity of the lever at the time that the highest pulse number was delivered, an additional pulse number ( 26 pulses per train, $130 \mathrm{~Hz}$ ) was included at the beginning of each pass; responses to this pulse number were not included in data analyses. On a given pass, each pulse number was tested during a single $45 \mathrm{sec}$ trial; the first $5 \mathrm{sec}$ of each trial were considered a "frequency adaptation" period, and only responses emitted during the last $40 \mathrm{sec}$ were used for analysis. Each trial was preceded by five noncontingent (priming) trains of stimulation that were identical to those available during the trial. A $30 \mathrm{sec}$ intertrial interval separated the testing of each pulse number. In each of the experiments reported here, the same range of pulse numbers (from 31 to 2 pulses per train) was tested during baseline (predrug) and drug conditions.

Data obtained from each pass generated a curve that described response rates as a function of pulse number (response-number curve). From each curve, an index of rewarding efficacy of the stimulation (reward threshold) was extrapolated and operationally defined as the pulse number that sustained a half-maximal rate of responding (M50 index). Training was considered complete when reward thresholds varied by $<0.1 \log$ units across several days. Each response-number curve yielded two measures: (1) rewarding efficacy of the stimulation (reward threshold) and (2) performance (maximal response rate). In each of the three experiments that follow, rats treated with haloperidol, clozapine, or vehicle were tested in parallel.

Experiment 1: acute haloperidol-clozapine. On the test day, four baseline response-number curves were first determined. Rats were then removed from their cages and injected subcutaneously with haloperidol $(7.8,15.63,31.25,62.5,125$, or $500 \mu \mathrm{g} / \mathrm{kg})$, clozapine $(5,10,20$ or 40 $\mathrm{mg} / \mathrm{kg})$, or vehicle $(0.3 \%$ tartaric acid in physiological saline). Each rat was tested with only one dose, and each dose was tested on a total of six rats. Rats were immediately returned to their respective test cages, and a response-number curve was determined every $30 \mathrm{~min}$, beginning immediately, for the next $6.5-10 \mathrm{hr}$. For any given curve, responding was not considered stable unless response rates for at least two consecutive pulse numbers were both greater than five responses per trial and were both higher than the half-maximal rate. In cases in which rats ceased responding, the entire range of pulse numbers was nonetheless tested. All rats received the same amount of priming stimulation (five trains), and no attempt was made to deliver extra stimulation to induce responding.

Experiment 2: test of depolarization block. Rats were divided into five groups $(n=12)$, each of which received a different drug regimen for $21 \mathrm{~d}$ : $500 \mu \mathrm{g} \cdot \mathrm{kg}^{-1} \cdot \mathrm{d}^{-1}$ haloperidol [chronic haloperidol (CHAL)], 20 $\mathrm{mg} \cdot \mathrm{kg}^{-1} \cdot \mathrm{d}^{-1}$ clozapine [chronic clozapine (CCLOZ)], 3 $\mathrm{mg} \cdot \mathrm{kg}^{-1} \cdot \mathrm{d}^{-1}$ tartaric acid [chronic vehicle $(\mathrm{CVEH})$ ], or CVEH for $20 \mathrm{~d}$ plus $500 \mu \mathrm{g} / \mathrm{kg}$ haloperidol or $20 \mathrm{mg} / \mathrm{kg}$ clozapine on day 21 (CVEHH or CVEHC, respectively). All drugs were administered subcutaneously, between 10 A.M. and 12 P.M. Some of the rats used in this second experiment had been used previously in experiment 1 . Rats that were treated with haloperidol in experiment $1(n=11)$ were assigned to the CHAL group, those treated with clozapine $(n=6)$ to the CCLOZ group, and those treated with vehicle to the CVEH $(n=4), \mathrm{CVEHH}$ $(n=4)$, or CVEHC $(n=6)$ groups. Before the start of the chronic drug regimen, four response-number curves were determined for each rat, and mean threshold and response rate values were calculated from the last three curves; this constituted baseline values for each rat. For those rats that had been tested previously in experiment 1 , baseline values for experiment 2 were the same as for experiment 1 .

Two hours after the 21st injection, rats were tested on two initial passes (at 120 and 140 min after injection). Immediately after the end of the second pass, half of the rats in each group $(n=6)$ were treated with an intraperitoneal injection of apomorphine (APO) and immediately tested on a third pass. In total, five doses of APO were administered $(12.7,25.4,50.8,101.7$, and $203.3 \mu \mathrm{g} / \mathrm{kg})$, each separated by a period of testing (a single pass) that lasted $\sim 20 \mathrm{~min}$. Cumulative administration of APO was used as a test of DB because this treatment has been shown previously to reverse DA cell DB in electrophysiological studies (Grace and Bunney, 1986). The second half of each group $(n=6)$ received five vehicle $(\mathrm{VEH})$ injections $(0.2 \mathrm{mg} / \mathrm{kg}$ ascorbic acid in physiological saline). After the last APO or VEH injection, rats were tested on three consecutive passes, followed by a single pass every $30 \mathrm{~min}$. In total, the test session lasted $\sim 4$ (CCLOZ and CVEHC) to $8 \mathrm{hr}$ (CHAL, CVEHH, and $\mathrm{CVEH}$ ).

Experiment 3: withdrawal from chronic haloperidol-clozapine. Beginning $24 \mathrm{hr}$ after the test of DB (experiment 2), all subjects were tested daily for an additional $28 \mathrm{~d}$. Testing consisted of four daily responsenumber curve determinations. Mean reward thresholds and maximal response rates were calculated only from the last three curves. For each rat, the baseline threshold and response rate values that were used in this experiment were the same as those of experiment 2.

Histology. Subjects were anesthetized with sodium pentobarbital, and the stimulation site was marked with a small lesion caused by passing direct anodal current through the stimulation electrode $(100 \mu \mathrm{A}, 20 \mathrm{sec})$. Rats were then intracardially perfused with saline, followed by $10 \%$ formalin in saline. Brains were removed and immersed in $10 \%$ formalin containing $3 \%$ potassium ferrocyanide, $3 \%$ potasssium ferricyanide, and $0.5 \%$ trichloroacetic acid; this resulted in a blue staining of the lesion site. Twenty-four hours later, brains were removed from this solution and kept in $10 \%$ formalin. Forty-eight hours before slicing, brains were immersed in $10 \%$ formalin containing $30 \%$ sucrose. Frozen brains were sliced into $40 \mu \mathrm{m}$ sections, dried, and stained with thionine for light microscopic verification.

Drugs. Haloperidol (Research Biochemicals Inc., Natick, MA) and clozapine (Sandoz, Dorval, Quebec) were dissolved in $0.9 \%$ saline containing $0.3 \%(w / v)$ tartaric acid. Apomorphine (Sigma, St. Louis, MO) 


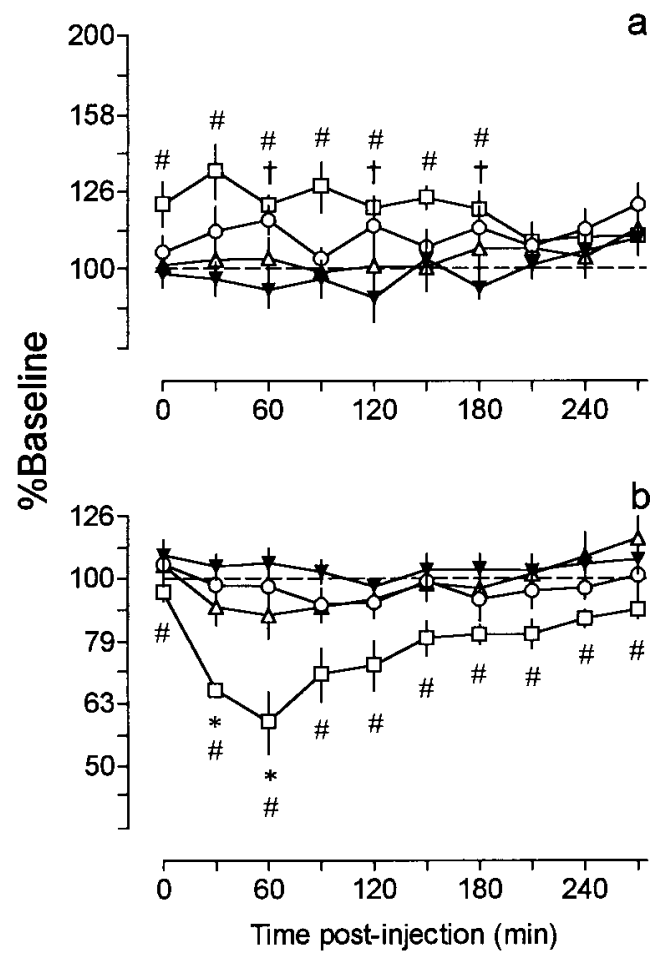

Figure 1. Time course of changes in reward thresholds $(a)$ and maximal response rates $(b)$ after treatment with haloperidol [7.8 $\mu \mathrm{g} / \mathrm{kg}(\bigcirc), 15.63$ $\mu \mathrm{g} / \mathrm{kg}(\triangle)$, and $31.25 \mu \mathrm{g} / \mathrm{kg}(\square)]$ and vehicle $(\boldsymbol{\nabla})$, as a function of time after injection. Each point $(n=6)$ is expressed as percent of baseline and represents the mean \pm SEM. Threshold and response rate data obtained from the vehicle (control) group are the same in this figure and Figure 2. Although the test session in the vehicle control condition lasted $630 \mathrm{~min}$, rats treated with the three lowest doses of haloperidol were tested only for $270 \mathrm{~min}$ because of the short time course of the effects of these doses. For clarity, only data collected between 0 and 270 min after vehicle injection are illustrated. For ease of comparison between reward thresholds and response rates, in all the figures, changes in the latter are also plotted on a semilogarithmic scale. $\dagger p<0.05,7.8 \mu \mathrm{g} / \mathrm{kg}$ versus vehicle; ${ }^{*} p<0.05$, $15.63 \mu \mathrm{g} / \mathrm{kg}$ versus vehicle; $\# p<0.05,31.25 \mu \mathrm{g} / \mathrm{kg}$ versus vehicle; Dunnett's tests.

was dissolved in $0.9 \%$ saline containing $0.02 \%$ (w/v) ascorbic acid. All drugs were aliquotted into $1 \mathrm{ml}$ Eppendorf tubes and kept frozen until just before use.

Data analysis. The data were analyzed with one-way ANOVA or two-way mixed ANOVA (with drug dose as the between-subject factor and time as the repeated measure). Post hoc analyses involving multiple comparisons with a single control group were made with Dunnett's tests, whereas multiple comparisons between two groups were done with Tukey tests. A priori comparisons were done with Student's $t$ tests with Bonferroni corrections. All probability values are two-tailed. In experiment 1 , the effects of acute treatment with $62.5,125$, and $500 \mu \mathrm{g} / \mathrm{kg}$ haloperidol were analyzed by calculating the $95 \%$ confidence interval for the vehicle control condition and determining which values in the three drug groups differed statistically.

\section{RESULTS}

\section{Experiment 1: acute haloperidol-clozapine}

The three lowest doses of haloperidol increased reward thresholds and reduced response rates. The largest increase in reward thresholds (33\%) was observed after $31.25 \mu \mathrm{g} / \mathrm{kg}$, an effect that lasted $\sim 180 \mathrm{~min}$ (Fig. 1a). Results of a two-way ANOVA revealed a significant effect of dose $\left(F_{(3,20)}=4.74 ; p<0.05\right)$ and a significant dose $\times$ time interaction $\left(F_{(27,180)}=1.55 ; p<0.05\right)$, but no effect of time $\left(F_{(9,180)}=0.86 ; p=0.56\right)$. Post hoc tests revealed that the $7.8 \mu \mathrm{g} / \mathrm{kg}$ dose caused a significant increase in reward thresholds at 60, 120, and $180 \mathrm{~min}$ and the $31.25 \mu \mathrm{g} / \mathrm{kg}$ dose at all time intervals between 0 and $180 \mathrm{~min}$. Reward thresholds were not altered after treatment with $15.63 \mu \mathrm{g} / \mathrm{kg}$. The greatest reduction in response rates $(41 \%)$ occurred $60 \mathrm{~min}$ after treatment with $31.25 \mu \mathrm{g} / \mathrm{kg}$ (Fig. $1 b$ ). A two-way ANOVA revealed a significant effect of dose $\left(F_{(3,20)}=7.24 ; p<0.01\right)$, time $\left(F_{(9,180)}=8.69 ; p<\right.$ $0.0001)$, and a dose $\times$ time interaction $\left(F_{(27,180)}=1.70 ; p<0.05\right)$. Post hoc tests revealed that response rates were significantly reduced between 30 and $60 \mathrm{~min}$ after treatment with $15.63 \mu \mathrm{g} / \mathrm{kg}$ and at all time intervals after $31.25 \mu \mathrm{g} / \mathrm{kg}$. Response rates did not change after treatment with $7.8 \mu \mathrm{g} / \mathrm{kg}$.

Treatment with the three highest doses of haloperidol caused some animals to cease responding (Fig. 2). Because of the low (e.g., $n=1$ ) and unequal number of animals responding at some time periods, the data could not be subjected to ANOVA. Instead, the $95 \%$ confidence interval for the vehicle data were calculated and used to determine significant differences between drug and vehicle groups. The $62.5 \mu \mathrm{g} / \mathrm{kg}$ dose produced a maximal increase of $125 \%$ in reward thresholds ( $30 \mathrm{~min}$ ) and reduced response rates by $65 \%$ (60 min) (Fig. $2 a, b)$. At this dose, five of the six rats ceased responding during at least one time interval, and when the behavior was restored, threshold values were not different from vehicle; response rates, however, remained significantly reduced throughout the entire session. At a dose of 125 $\mu \mathrm{g} / \mathrm{kg}$, haloperidol caused a maximal increase of $98 \%$ in reward thresholds (first point) and reduced response rates by $80 \%$ (30 min) (Fig. $2 c, d$ ). In five of six animals, responding ceased for at least $1.5 \mathrm{hr}$ (from 30 to $120 \mathrm{~min}$ after injection). At this dose, the inhibitory effects of haloperidol had a similar time course on thresholds and response rates. Treatment with $500 \mu \mathrm{g} / \mathrm{kg}$ caused a maximal increase of $197 \%$ in reward thresholds (first point) and reduced maximal response rates by $75 \%$ (480 min) (Fig. 2e,f). At this dose, one animal stopped responding immediately after injection, and another never resumed, even after $10.5 \mathrm{hr}$. None of the rats treated with $500 \mu \mathrm{g} / \mathrm{kg}$ responded between 30 and 360 min after injection. Again, maximal response rates remained significantly reduced throughout the entire test session and, compared with reward thresholds, were characterized by a late and gradual recovery.

Immediately after injection (first point), clozapine doses of 5-40 $\mathrm{mg} / \mathrm{kg}$ increased reward thresholds dose-dependently, an effect that reached a maximum ( $82 \%$ increase) at the highest dose (Fig. 3a). Results of a two-way ANOVA revealed a significant effect of dose $\left(F_{(4,25)}=7.85 ; p<0.001\right)$, time $\left(F_{(13,325)}=3.87\right.$; $p<0.0001)$, and a dose $\times$ time interaction $\left(F_{(52,325)}=2.06 ; p<\right.$ $0.0001)$. Post hoc tests revealed that reward thresholds were not statistically different from vehicle control values after the $5 \mathrm{mg} / \mathrm{kg}$ dose but were significantly higher immediately after injection of $10 \mathrm{mg} / \mathrm{kg}$, and at all time intervals except 60 and $240 \mathrm{~min}$ after 20 $\mathrm{mg} / \mathrm{kg}$. The highest dose of clozapine $(40 \mathrm{mg} / \mathrm{kg})$ caused a significant increase in reward thresholds between 0 and $150 \mathrm{~min}$ and at $210 \mathrm{~min}$ after injection. Clozapine also reduced maximal response rates, an effect that reached a maximum (50\% decrease) $30 \mathrm{~min}$ after treatment with $40 \mathrm{mg} / \mathrm{kg}$ (Fig. 3b). A two-way ANOVA revealed a significant effect of dose $\left(F_{(4,25)}=3.00 ; p<\right.$ $0.05)$, time $\left(F_{(13,325)}=7.87 ; p<0.0001\right)$, and a dose $\times$ time interaction $\left(F_{(52,325)}=2.09 ; p<0.0001\right)$. Post hoc tests revealed that clozapine reduced maximal response rates significantly between 30 and $180 \mathrm{~min}$ after 10 and $40 \mathrm{mg} / \mathrm{kg}$, and between 30 and $120 \mathrm{~min}$ and between 180 and $240 \mathrm{~min}$ after $20 \mathrm{mg} / \mathrm{kg}$. 


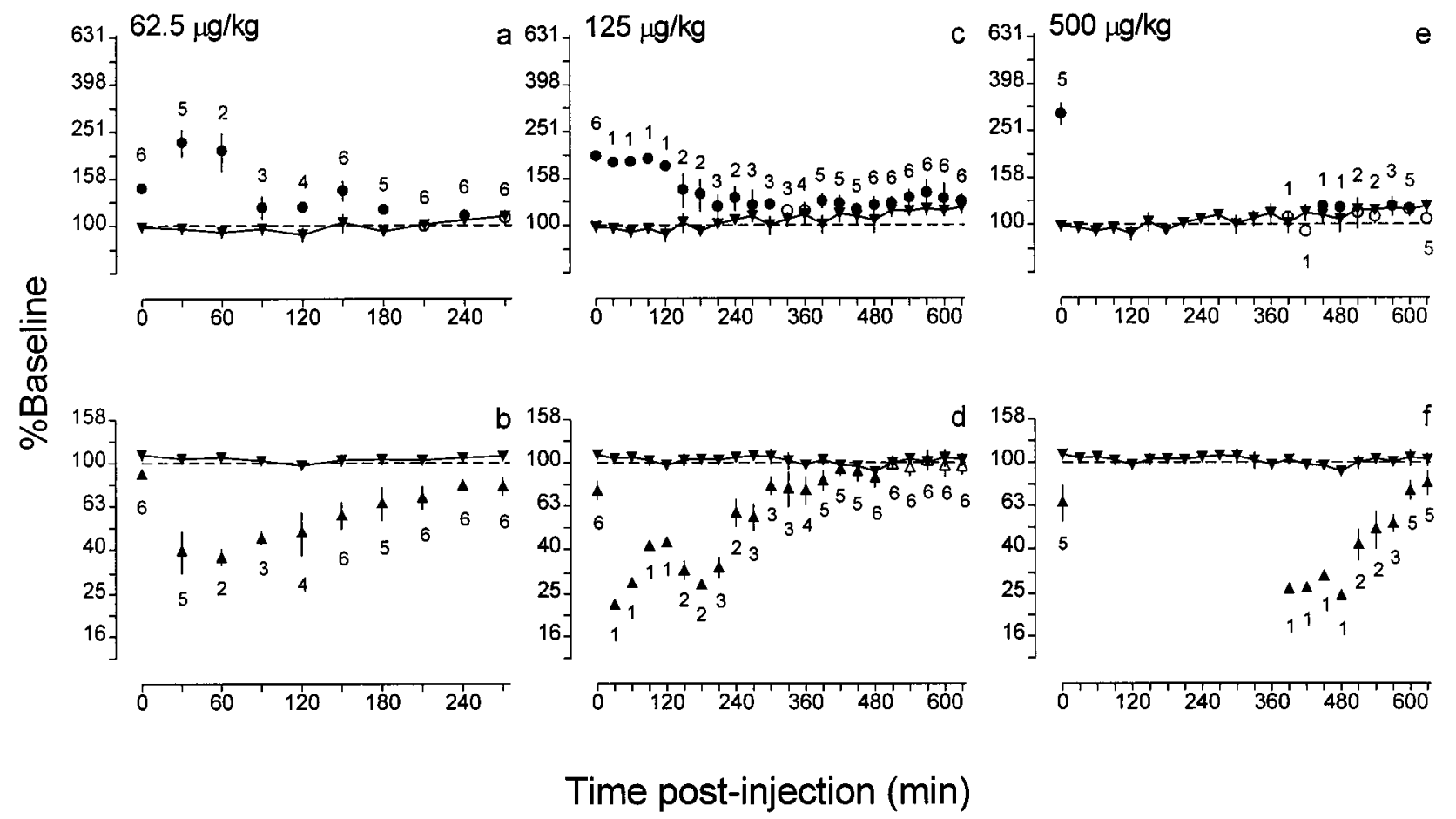

Figure 2. Time course of changes in reward thresholds $(\bigcirc$, top $)$ and maximal response rates $(\triangle$, bottom $)$ after treatment with haloperidol (62.5, 125 , and $500 \mu \mathrm{g} / \mathrm{kg}$ ) and vehicle $(\boldsymbol{\nabla})$, as a function of time after injection. Numbers above or below each point indicate the number of rats responding at each time interval. Each point $(n=6)$ is expressed as percent of baseline and represents the mean \pm SEM. Filled symbols in the drug conditions indicate values that lie beyond the $95 \%$ confidence interval of the vehicle curve $(p<0.05)$.

\section{Experiment 2: test of depolarization block Effect of $A P O$ on $C V E H$-treated rats}

In animals treated chronically with vehicle $(\mathrm{CVEH}), \mathrm{APO}$ increased reward thresholds by $32 \%$ (Fig. $4 a$ ) and reduced maximal response rates by $23 \%$ (Fig. $4 b$ ). During this time, animals displayed hypomobility. A two-way ANOVA performed on threshold data did not reveal an effect of treatment $\left(F_{(1,10)}=0.04 ; p=\right.$ $0.84)$, time $\left(F_{(19,190)}=1.25 ; p=0.23\right)$, or a treatment $\times$ time interaction $\left(F_{(19,190)}=1.16 ; p=0.29\right)$. A two-way ANOVA performed on response rate data did not reveal an effect of treatment $(\mathrm{F}(1,10)=0.28, p=0.61)$ or time $\left(F_{(19,190)}=1.06 ; p=\right.$ $0.40)$ but yielded a significant treatment $\times$ time interaction $\left(F_{(19,190)}=3.03 ; p<0.0001\right)$. Post hoc tests showed that, compared with VEH-treated rats, maximal response rates in the APOtreated group were significantly lower at 120, 200, and $220 \mathrm{~min}$.

\section{Effect of APO on CHAL-treated rats}

Eight of the 12 rats treated chronically with haloperidol (CHAL, $500 \mu \mathrm{g} / \mathrm{kg}$ ) did not initially respond for the stimulation (Figs. $5 b, c, e, f, 6 a-c, e)$, and three others stopped responding after behavioral testing had begun (Figs. $5 a, d, 6 d$ ). One rat responded at all time periods (Fig. $6 f$ ). Every rat (six of six) treated with APO resumed responding before the end of the test session, 200-400 min after the 21st injection of haloperidol. In contrast, treatment with VEH restored responding in only two of four rats, both at $490 \mathrm{~min}$ after the 21st injection of haloperidol (Fig. $6 b, c)$. Note that responding was considered to have ceased when the animals failed to lever press on two consecutive passes. Likewise, the behavior was not considered restored unless it was present on two consecutive passes.

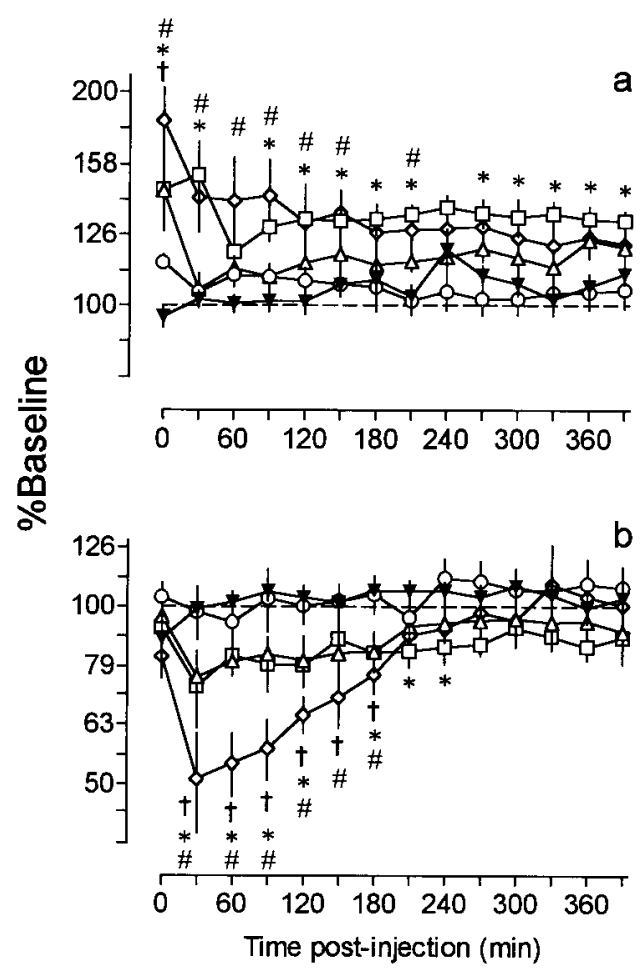

Figure 3. Time course of changes in reward thresholds $(a)$ and maximal response rates $(b)$ after treatment with clozapine $[5 \mathrm{mg} / \mathrm{kg}(\bigcirc), 10 \mathrm{mg} / \mathrm{kg}$ $(\triangle), 20 \mathrm{mg} / \mathrm{kg}(\square)$, and $40 \mathrm{mg} / \mathrm{kg}(\diamond)]$ and vehicle $(\nabla)$, as a function of time after injection. Each point $(n=6)$ is expressed as percent of baseline and represents the mean \pm SEM. $\dagger p<0.05,10 \mathrm{mg} / \mathrm{kg}$ versus vehicle; ${ }^{*} p<$ $0.05,20 \mathrm{mg} / \mathrm{kg}$ versus vehicle; $\# p<0.05,40 \mathrm{mg} / \mathrm{kg}$ versus vehicle; Dunnett's tests. 


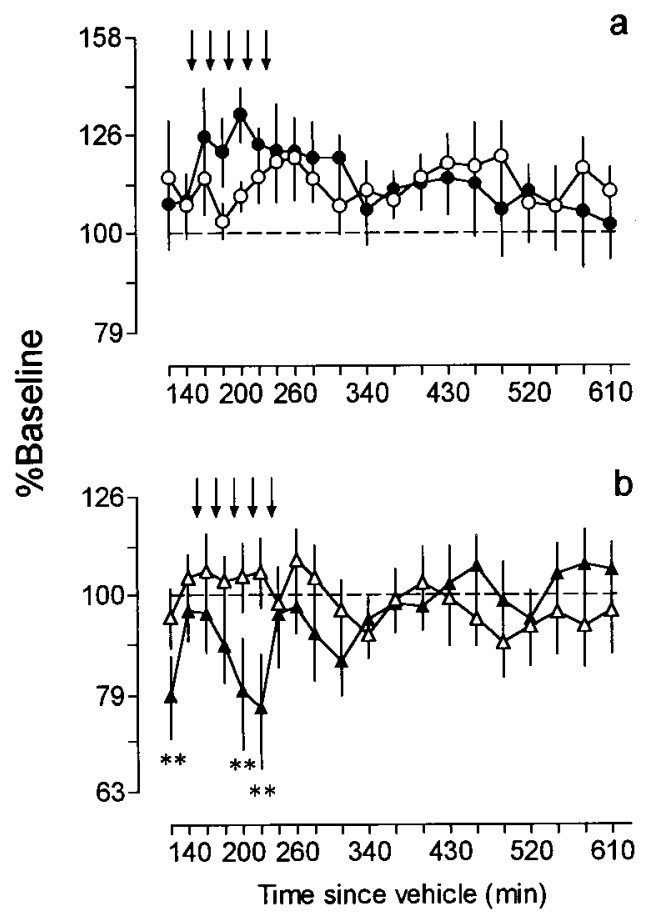

Figure 4. Time course of changes in reward thresholds $(a)$ and maximal response rates $(b)$ after treatment with cumulative doses $(12.7,25.4,50.8$, 101.7, and $203.3 \mu \mathrm{g} / \mathrm{kg}$ ) of APO or VEH in CVEH-treated rats. Values are expressed as percent of baseline and are plotted as a function of time since the 21 st injection of vehicle. Each point $(n=6)$ represents the mean \pm SEM. Arrows indicate times of APO or VEH injection. Thresholds: @, CVEH+APO;, $\mathrm{CVEH}+\mathrm{VEH}$. Response rates: $\boldsymbol{\Delta}$, $\mathrm{CVEH}+\mathrm{APO} ; \triangle \mathrm{CVEH}+\mathrm{VEH} .{ }^{* *} p<0.01$; Tukey tests.

\section{Effect of APO on CVEHH-treated rats}

Of the 12 rats that were treated chronically with vehicle followed by acute haloperidol $(500 \mu \mathrm{g} / \mathrm{kg})$ on day $21(\mathrm{CVEHH})$, nine did not initially respond (Figs. $7 a, c-f, 8 a, c, d, f$ ), and the remaining three stopped after the first pass (Figs. $7 b, 8 b, e$ ). Responding resumed in only 4 of 12 rats: two after treatment with APO (Fig. $7 e, f)$ and two after VEH (Fig. 8e,f). Two additional rats responded during single passes only (Fig. $8 c, d$ ).

The bar graph in Figure 9 summarizes the above findings by illustrating the percentage of rats in each group that resumed lever pressing and the mean time at which this occurred. A $\chi^{2}$ test revealed that a significantly higher number of $\mathrm{CHAL}+\mathrm{APO}-$ treated rats resumed responding compared with those treated with $\mathrm{CHAL}+\mathrm{VEH}, \mathrm{CVEHH}+\mathrm{APO}$, or $\mathrm{CVEHH}+\mathrm{VEH}(p<$ $0.05)$. Note that the effectiveness of APO in restoring the behavioral response was seen only in CHAL-treated rats, because the number of $\mathrm{CVEHH}+\mathrm{APO}$-treated rats that resumed responding did not differ from those treated with CVEHH+VEH. Last, those animals treated with $\mathrm{CHAL}+\mathrm{APO}$ resumed responding sooner $(282 \pm 33.90 \mathrm{~min})$ than those treated with CHAL+VEH $\left(490 \mathrm{~min}\right.$; Bonferroni $\left.t_{(6)}=3.36 ; p<0.05\right), \mathrm{CVEHH}+\mathrm{APO}$ $\left(475 \pm 45 \mathrm{~min}\right.$; Bonferroni $t_{(6)}=2.95$; NS), or CVEHH+VEH $\left(460 \pm 35 \mathrm{~min}\right.$; Bonferroni $t_{(6)}=2.80$; NS $)$.

\section{Effect of APO on CCLOZ- and CVEHC-treated rats}

None of the rats treated with CCLOZ $(20 \mathrm{mg} / \mathrm{kg})$ ceased responding at any time interval (Fig. 10a,b). A two-way ANOVA performed on threshold data did not reveal a significant effect of treatment $\left(F_{(1,10)}=0.09 ; p=0.77\right)$, but a significant effect of time $\left(F_{(11,110)}=7.09 ; p<0.0001\right)$ and a significant treatment $\times$ time interaction $\left(F_{(11,110)}=2.56 ; p<0.01\right)$ were found. Post hoc tests indicated that, in animals treated with APO, thresholds were significantly lower than in VEH-treated animals at 310 and 340 min (Fig. 10a). A two-way ANOVA on response rate data did not reveal any effect of treatment $\left(F_{(1,10)}=0.55 ; p=0.47\right)$, time $\left(F_{(11,110)}=1.09 ; p=0.37\right)$, or a treatment $\times$ time interaction $\left(F_{(11,110)}=0.88 ; p=0.56\right)$ (Fig. 10b). Likewise, animals treated chronically with vehicle followed by acute clozapine $(20 \mathrm{mg} / \mathrm{kg})$ on day 21 (CVEHC) responded at all time periods (Fig. 10c,d). A two-way ANOVA performed on threshold data did not reveal an effect of treatment $\left(F_{(1,10)}=0.36 ; p=0.56\right)$, time $\left(F_{(11,110)}=\right.$ $1.88 ; p=0.05)$, or a treatment $\times$ time interaction $\left(F_{(11,110)}\right.$ $=1.56 ; p=0.12$ ) (Fig. 10c). A two-way ANOVA performed on response rate data yielded a significant effect of time $\left(F_{(11,110)}=\right.$ 13.23; $p<0.0001)$ and a treatment $\times$ time interaction $\left(F_{(11,110)}\right.$ $=3.35 ; p<0.001)$ but no effect of treatment $\left(F_{(1,10)}=1.93 ; p=\right.$ 0.19). Post hoc tests revealed that maximal response rates differed significantly between APO- and VEH-treated rats 140-370 min after clozapine (Fig. 10d). Inspection of data from individual rats revealed that the high response rates in the $\mathrm{CVEHC}+\mathrm{VEH}$ group are mainly caused by the unusually high (67-161\% above baseline) response rates of a single rat. If the contribution of this rat is removed, the difference between APO- and VEH-treated groups disappears between 120 and $160 \mathrm{~min}$ and is reduced by approximately half at all other time intervals (data not shown).

Chronic drug treatment resulted in differences in animal weights. Results of a one-way ANOVA performed on total percent weight increase on day 21 revealed a significant effect of dose $\left(F_{(4,55)}=15.58 ; p<0.0001\right)$. Post hoc tests showed that, compared with the CVEH group $(16.9 \pm 1.0 \%)$, total weight gain was significantly lower in the CHAL $(12.9 \pm 1.0 \% ; p<0.05)$ and CCLOZ $(13 \pm 1.0 \% ; p<0.05)$ groups and significantly higher in the CVEHH group $(21.5 \pm 1.0 ; p<0.01)$. Animal weights in the CVEHC group $(19 \pm 0.58 \%)$ did not differ from control.

\section{Experiment 3: withdrawal from chronic haloperidol-clozapine}

Possible differences in baseline reward thresholds or maximal response rates as a consequence of treatment with APO or VEH in experiment 2 were determined separately in each drug group (CHAL, CCLOZ, and CVEH) with two-way ANOVA. These analyses revealed no significant effect of treatment or treatment $X$ time interactions for either reward thresholds or maximal response rates. Consequently, data from rats preexposed to APO or VEH were pooled within each drug group ( $n=12$ in each group).

Inspection of individual response-number curves revealed time-dependent transformations in the shape of the curves. These transformations were particularly pronounced in the CHALtreated group and were characterized by a selective increase in response rates at high stimulation frequencies (i.e., in the asymptotic portion of the curves). The nature of these transformations violates a major assumption that validates the use of M50 (halfmaximal rate of responding) as a reliable index of the rewarding efficacy of the stimulation. Consequently, reward thresholds were inferred from the pulse number that just fails to induce responding (theta zero index); this behavioral criterion is insensitive to nonscalar transformations of the response-number curve as detected in this experiment (Miliaressis et al., 1986). 


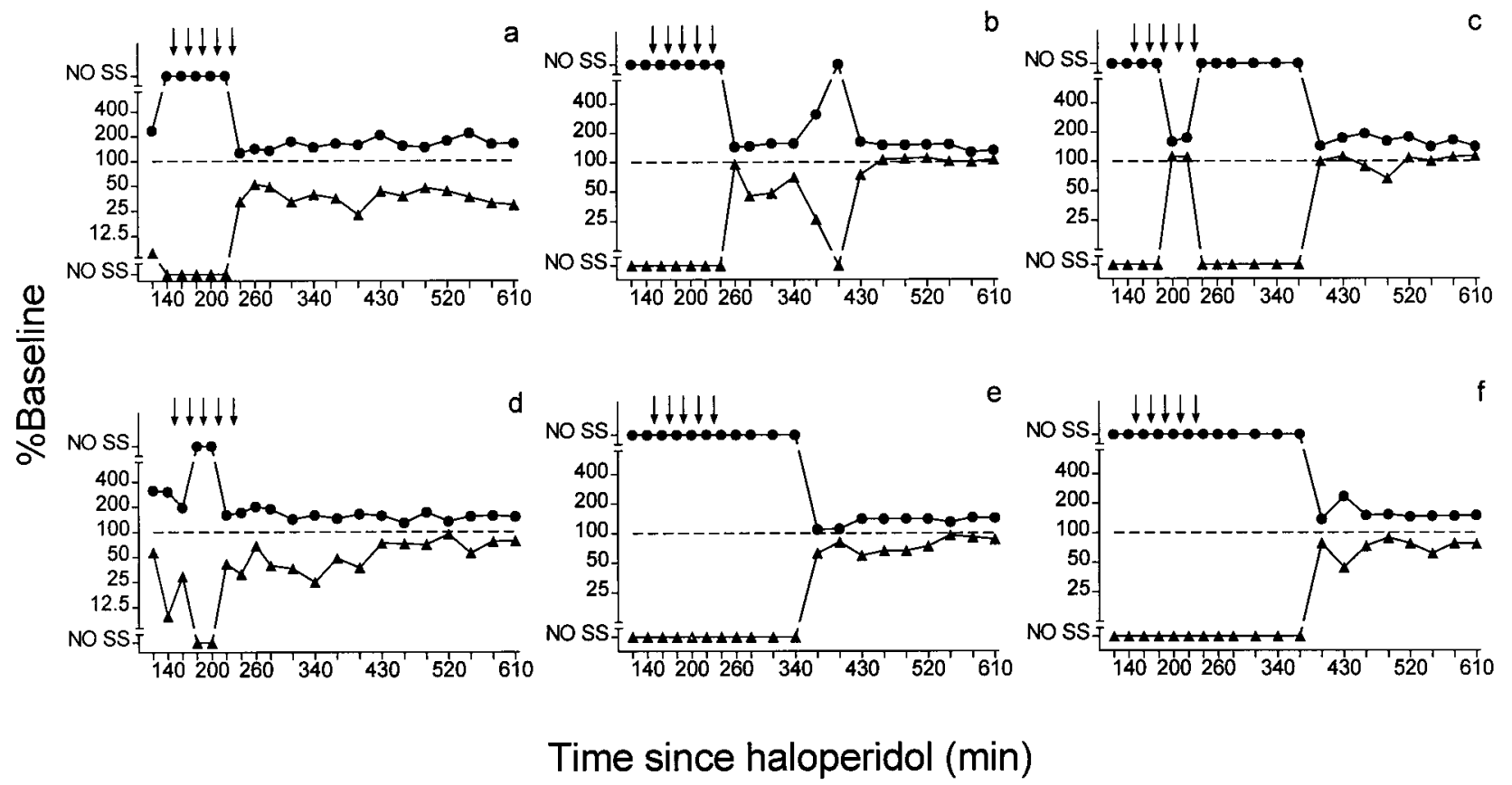

Figure 5. Time course of changes in reward thresholds $(\bullet)$ and maximal response rates $(\mathbf{\Delta})$ after administration of APO to rats treated with CHAL $(500 \mu \mathrm{g} / \mathrm{kg})$. Data obtained from individual animals are shown. Values are expressed as percent of baseline and are plotted as a function of time since the 21st injection of haloperidol. Arrows indicate times of APO injection. NO SS, No self-stimulation.

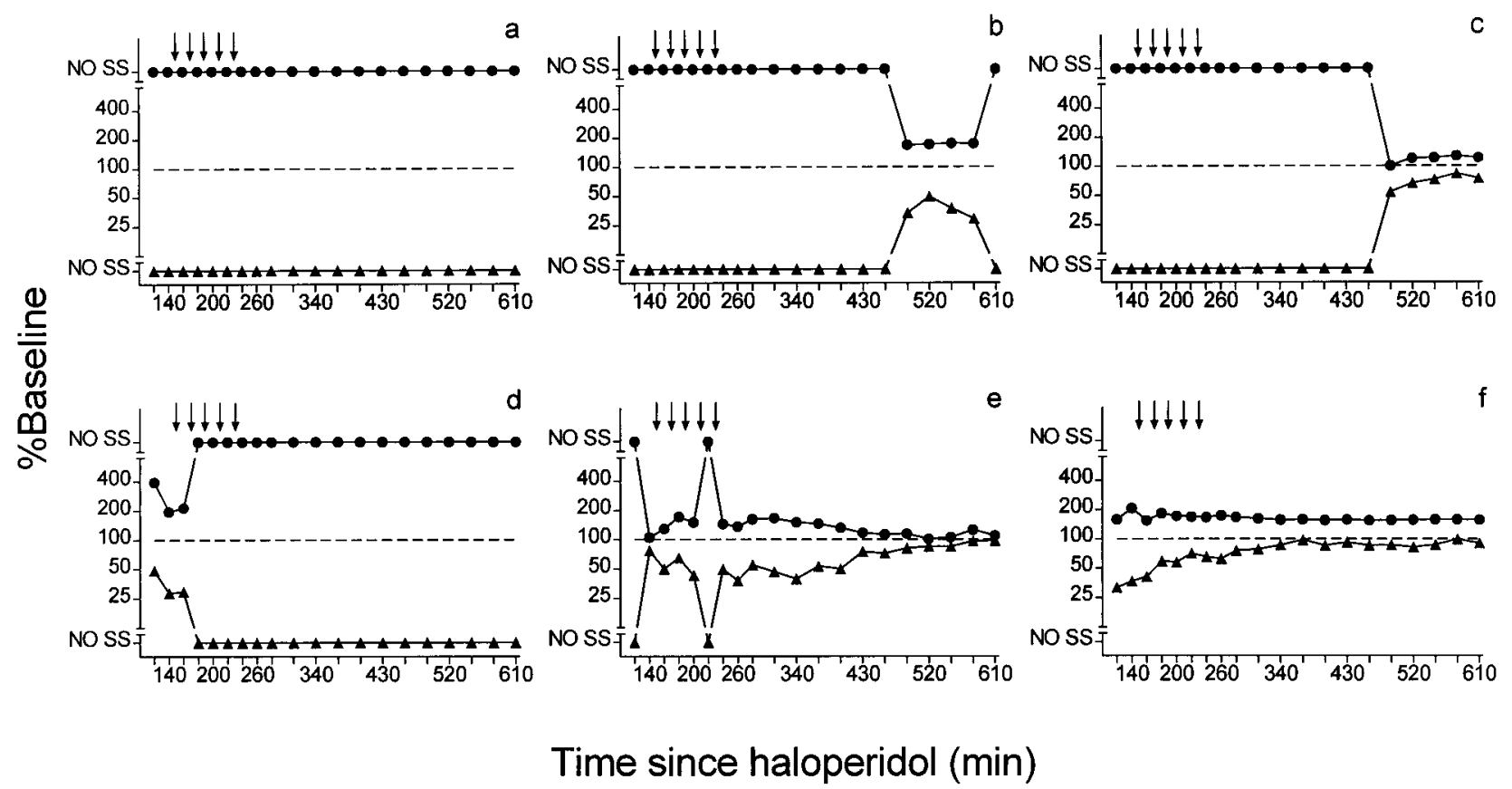

Figure 6. Time course of changes in reward thresholds $(\bullet)$ and maximal response rates $(\mathbf{\Delta})$ after administration of VEH to rats treated with $\mathrm{CHAL}$ $(500 \mu \mathrm{g} / \mathrm{kg})$. Data obtained from individual animals are shown. Values are expressed as percent of baseline and are plotted as a function of time since the 21 st injection of haloperidol. Arrows indicate times of VEH injection. NO SS, No self-stimulation.

A two-way ANOVA performed on reward thresholds did not reveal a significant effect of treatment $\left(F_{(2,33)}=0.49 ; p=0.61\right)$ or a treatment $\times$ time interaction $\left(F_{(54,891)}=1.21 ; p=0.15\right)$, but a significant effect of time was found $\left(F_{(27,891)}=3.89 ; p<0.01\right)$ (Fig. 11a). A two-way ANOVA performed on maximal response rates did not reveal a significant effect of treatment $\left(F_{(2,33)}=0.41\right.$; $p=0.66)$, but a significant effect of time $\left(F_{(27,891)}=1.58 ; p<\right.$
$0.05)$ and a treatment $\times$ time interaction were found $\left(F_{(54,891)}=\right.$ 3.63; $p<0.01)$. Post hoc tests revealed that maximal response rates after withdrawal from $\mathrm{CHAL}$ treatment were significantly higher than CVEH values on days 3-13 and 15 and were significantly lower on days 24, 27, and 28 (Fig. 11b). Response rates increased in all but two CHAL-treated animals; in these two rats, response rates were reduced by $\sim 33$ and $40 \%$. The magnitude of 


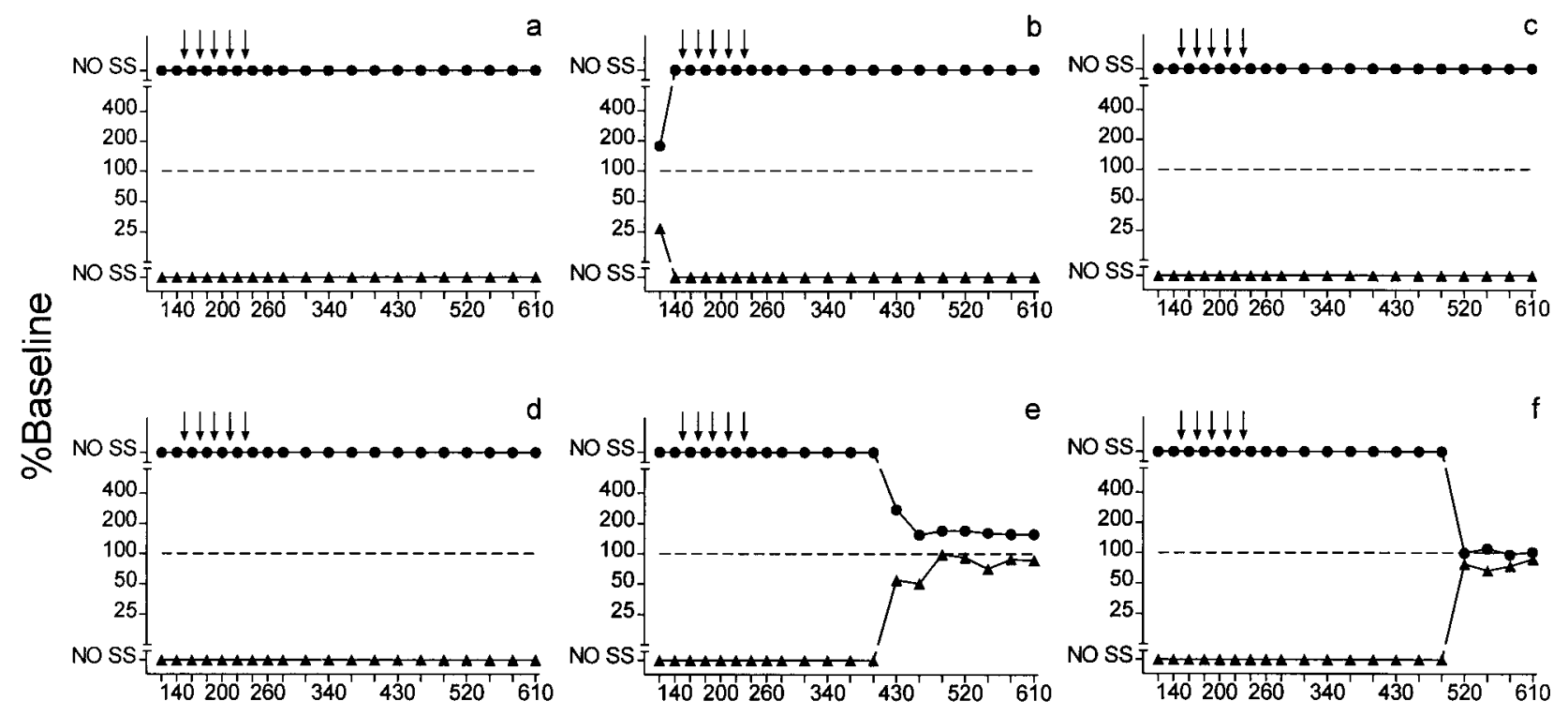

\section{Time since haloperidol ( $\min )$}

Figure 7. Time course of changes in reward thresholds $(\bullet)$ and maximal response rates $(\mathbf{\Delta})$ after administration of APO to rats treated with CVEHH (chronic vehicle for $20 \mathrm{~d}$ plus $500 \mu \mathrm{g} / \mathrm{kg}$ haloperidol on day 21). Data obtained from individual animals are shown. Values are expressed as percent of baseline and are plotted as a function of time since injection of haloperidol. Arrows indicate times of APO injection. NO SS, No self-stimulation.
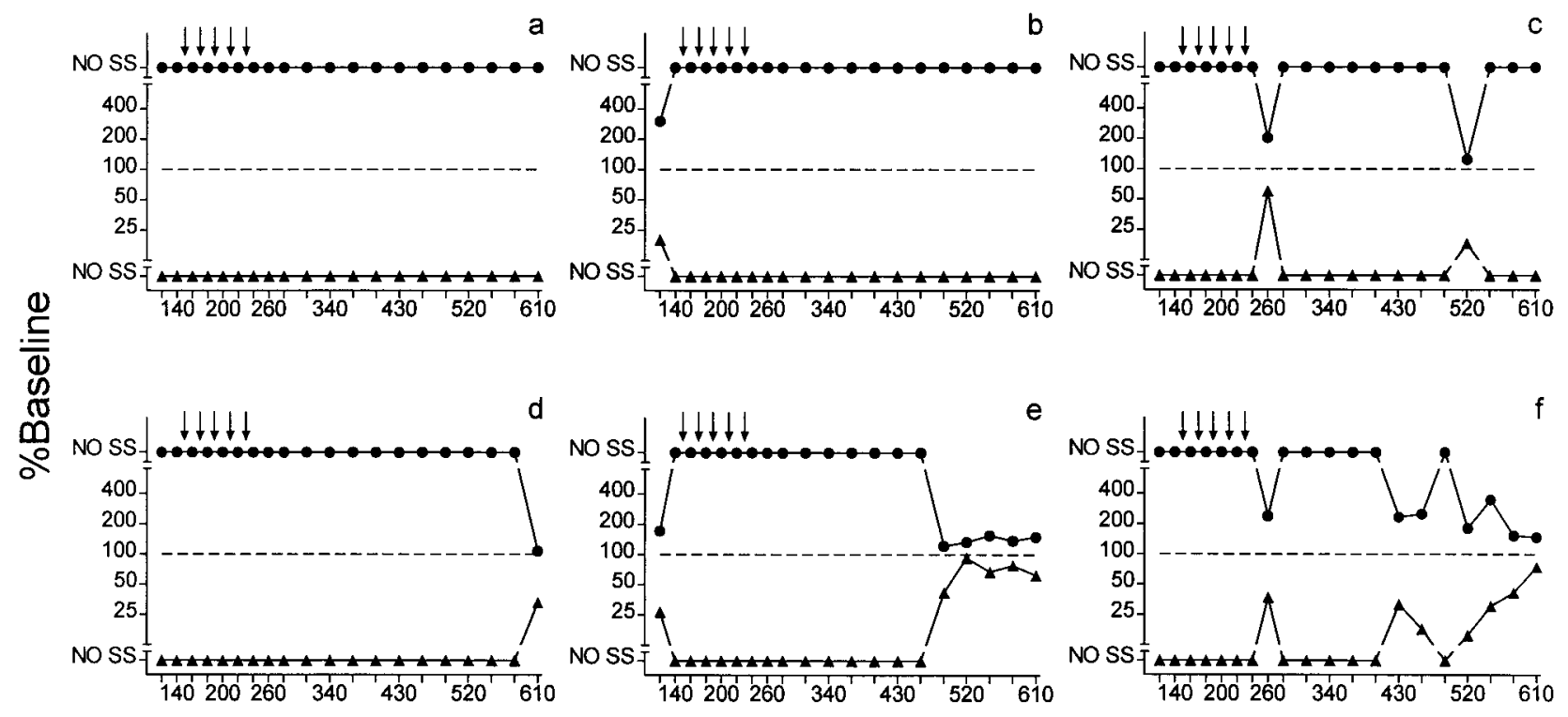

Time since haloperidol $(\mathrm{min})$

Figure 8. Time course of changes in reward thresholds $(\bullet)$ and maximal response rates $(\mathbf{\Delta})$ after administration of VEH to rats treated with CVEHH (chronic vehicle for $20 \mathrm{~d}$ plus $500 \mu \mathrm{g} / \mathrm{kg}$ haloperidol on day 21). Data obtained from individual animals are shown. Values are expressed as percent of baseline and are plotted as a function of time since injection of haloperidol. Arrows indicate times of VEH injection. NO SS, No self-stimulation.

the maximum increase in response rates was variable in the remaining 10 animals, ranging from 12 to $99 \%$.

\section{DISCUSSION}

\section{Acute haloperidol-clozapine}

Acute treatment with haloperidol and clozapine resulted in significant increases in thresholds and reductions in response rates, suggesting that these drugs attenuated both rewarding efficacy and performance, respectively. However, haloperidol had a longer-lasting inhibitory effect on response rates. This effect was most clearly observed after treatment with the three highest doses of haloperidol and was characterized by a fast and near-complete restoration of reward thresholds but a slow and gradual recovery of maximal response rates. The inhibitory effects of clozapine on 


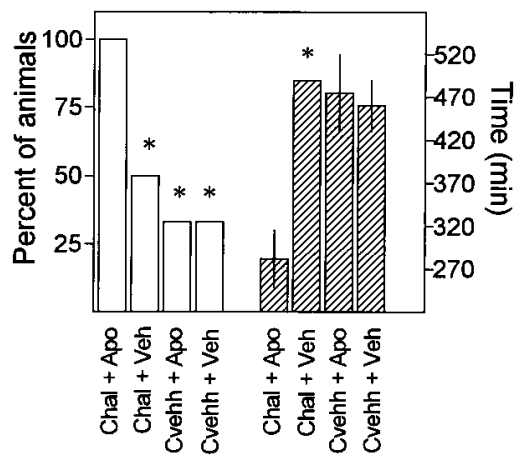

Figure 9. Percentage of animals in each drug condition that resumed responding (on at least 2 consecutive passes) before the end of the test session (open bars) and the times at which this occurred (hatched bars; bar heights represent mean $\pm \mathrm{SEM}) .{ }^{*} p<0.05 ; \chi^{2}$ test.

thresholds and response rates differed from those of haloperidol. First, immediately after injection, the three highest doses of clozapine caused significant increases in thresholds in the absence of any substantial reduction in response rates; these were significantly reduced only after $30 \mathrm{~min}$. Second, clozapine had a longerlasting inhibitory effect on thresholds than on response rates. Third, the magnitude of the effect of clozapine on reward thresholds appeared to saturate with $20 \mathrm{mg} / \mathrm{kg}$, whereas the peak reduction in response rates produced by $40 \mathrm{mg} / \mathrm{kg}$ was approximately twice that of $20 \mathrm{mg} / \mathrm{kg}$. Together, these findings strongly suggest that the underlying rewarding effect and the animals' capacity to respond are mediated by different neural substrates and that these are differentially sensitive to the inhibitory effects of haloperidol and clozapine.

\section{Test of depolarization block}

The primary aim of this experiment was to determine whether CHAL treatment leads to DB of midbrain DA cells in intact, freely moving animals. We chose EBS as a behavioral paradigm because it is sensitive to changes in DA neurotransmission (Wise and Rompré, 1989; Wise, 1996); we chose APO to test for DB because it hyperpolarizes DA cells (Grace and Bunney, 1985, 1986; Freeman and Bunney, 1987; Akaoka et al., 1992) and has been shown to reverse DB in electrophysiological studies (Bunney and Grace, 1978; White and Wang, 1983a,b; Grace and Bunney, 1986). Two main findings suggest that CHAL treatment resulted in DB of midbrain DA cells. First, the majority of CHAL-treated rats did not respond when initially tested, but the behavior was reinstated in every rat treated with APO. Thus, although APO by itself inhibited responding, it restored the behavior in rats treated with CHAL. Moreover, the effectiveness of APO in repolarizing the membrane potential of DA cells in a state to DB predicts a faster behavioral restoration in CHAL-treated rats injected with APO than in those injected with VEH; this effect was also observed in experiment 2. In fact, the two CHAL-treated rats that resumed responding after $\mathrm{VEH}$ injections did so at times that coincide with the spontaneous recovery seen in acutely treated rats (compare Fig. 6 with Figs. 2 and 8). Second, APO restored responding in rats treated chronically, but not acutely, with haloperidol. In fact, in the group of rats treated with $\mathrm{CVEHH}+\mathrm{APO}$, only $33 \%$ (two of six) resumed responding, whereas all rats (six of six) treated with CHAL+APO did so. The differential effect of APO in animals treated acutely and chronically with haloperidol suggests that the mechanisms underlying response cessation in these two groups are different. In the CVEHH-treated group, the number of rats that resumed re-

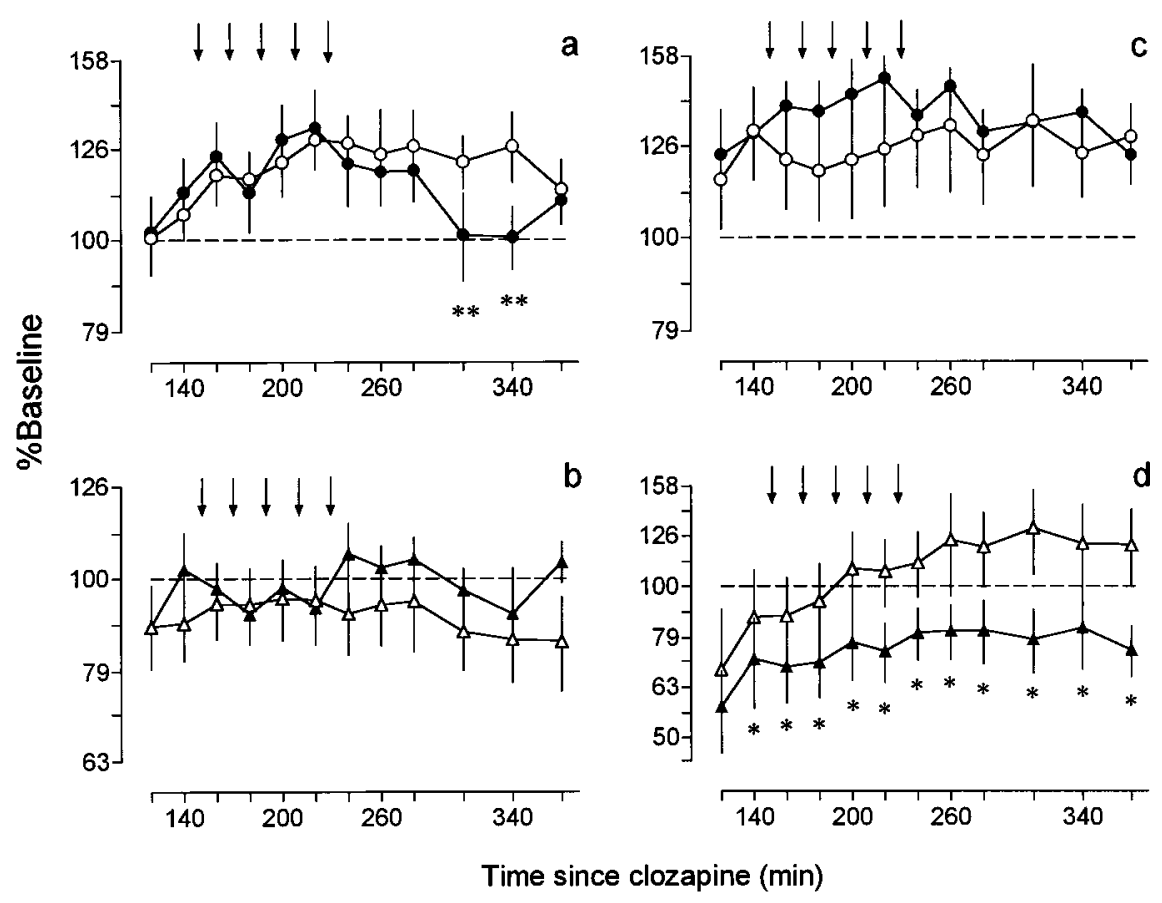

Figure 10. Left, Time course of changes in reward thresholds $(a)$ and maximal response rates $(b)$ after administration of APO or VEH to rats treated with CCLOZ $(20 \mathrm{mg} / \mathrm{kg})$. Thresholds: $\bullet$, CCLOZ+APO; O, CCLOZ+VEH. Response rates: $\Delta$, CCLOZ+APO; $\triangle$, CCLOZ+VEH. Right, Time course of changes in reward thresholds $(c)$ and maximal response rates $(d)$ after administration of APO or VEH to rats treated with CVEHC (chronic vehicle for $20 \mathrm{~d}$ plus $20 \mathrm{mg} / \mathrm{kg}$ clozapine on day 21). Thresholds: $\bullet$, CVEHC+APO; O, CVEHC+VEH. Response rates: $\boldsymbol{\Delta}$, CVEHC+APO; $\triangle$, $\mathrm{CVEHC}+\mathrm{VEH}$. Values are expressed as percent of baseline and are plotted as a function of time after injection of clozapine. Each point $(n=6)$ represents the mean \pm SEM. Arrows indicate times of APO or VEH injection. * $p<0.05 ; * *<0.01$; Tukey tests. 


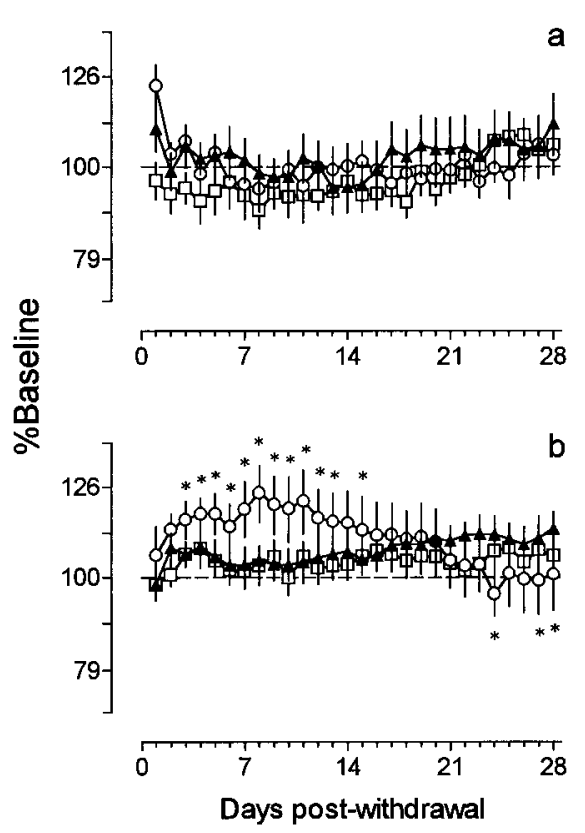

Figure 11. Time course of changes in reward thresholds $(a)$ and maximal response rates $(b)$ after withdrawal from CHAL $(\bigcirc), \mathrm{CCLOZ}(\square)$, and $\mathrm{CVEH}(\boldsymbol{\Delta})$ treatment. Values are expressed as percent of baseline and are plotted as a function of days after drug withdrawal. Each point $(n=$ 12) represents the mean \pm SEM. * $p<0.05$; Dunnett's tests.

sponding after APO or VEH did not differ, and the times at which responding resumed were also very similar between these and rats treated with $500 \mu \mathrm{g} / \mathrm{kg}$ haloperidol in experiment 1 (Fig. 2 ). These findings suggest that the absence of responding in CVEHH-treated animals reflects (1) blockade of a significant proportion of postsynaptic DA receptors by haloperidol and (2) the inefficiency of APO in displacing the antagonist from postsynaptic receptor sites. Indeed, $2 \mathrm{hr}$ after an acute subcutaneous injection of $500 \mu \mathrm{g} / \mathrm{kg}$ haloperidol, $\sim 80 \%$ of striatal DA D2 receptors are still occupied (Schotte et al., 1993). Conversely, the effectiveness of APO in reinstating responding in CHAL-treated rats, despite the continued presence of haloperidol, suggests DB in addition to blockade of postsynaptic receptors. Under these conditions, APO reinstates firing activity in previously inactivated DA cells, an effect that may be sufficient to overcome the postsynaptic DA receptor blockade by haloperidol.

Alternatively, the effect of APO in CHAL-treated rats may have been caused by direct stimulation of upregulated postsynaptic DA receptors (Burt et al., 1977). Although the specific mechanism of action of APO cannot be determined solely on the basis of the present behavioral results, two main observations suggest that the contribution of direct postsynaptic stimulation by APO was likely minimal. First, despite the availability of unoccupied postsynaptic receptor sites in CVEH-treated rats, APO had an inhibitory effect on responding, suggesting predominant stimulation of DA autoreceptors (Fouriezos and Francis, 1992). Although the total cumulative dose of APO used in the present work $(0.39 \mathrm{mg} / \mathrm{kg})$ is within the range of doses known to stimulate postsynaptic DA receptors when administered in a bolus subcutaneous injection (Robertson and Macdonald, 1986), intraperitoneal administration results in 5-fold to 12 -fold reductions in the stimulatory potency of APO (Barros et al., 1989). In addition, the brain elimination half-life of APO is $\sim 25 \mathrm{~min}$ (Melzacka et al., 1978), suggesting submaximal summation between successive

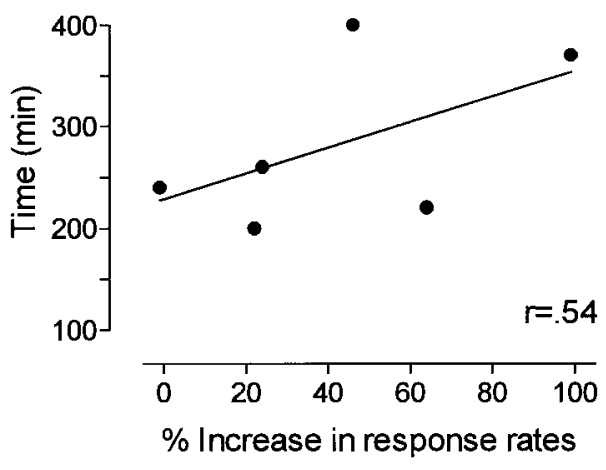

Figure 12. Correlation between time (in minutes) of resumed responding in the six animals treated with CHAL + APO in experiment 2 and their highest degree of behavioral supersensitivity (percent of increase in maximal response rates) in experiment 3 .

doses of APO (i.e., administration of each dose was separated by $\sim 20 \mathrm{~min}$ ). Second, chronic blockade of DA D2 receptors also causes upregulation of somatodendritic (Stefanini et al., 1991) and terminal DA autoreceptors (Nowak et al., 1983; Saller and Salama, 1985). In fact, upregulation of DA D2 receptors in substantia nigra appears to be greater than in striatum (76 vs 38\%, respectively) (Stefanini et al., 1991). Greater upregulation of somatodendritic autoreceptors, together with the greater sensitivity of these to DA and DA agonists (Skirboll et al., 1979), suggests a predominant role of these autoreceptors, rather than postsynaptic sites, in reinstating the behavior.

All rats treated with CCLOZ responded throughout the test session. However, the increase in reward thresholds seen in CCLOZ-treated rats was reversed by APO but not by VEH. In addition, APO restored threshold values in rats treated chronically, but not acutely, with clozapine. On the other hand, neither CCLOZ nor APO had any substantial effect on response rates. These findings may constitute a behavioral counterpart to electrophysiological work. Electrophysiological studies have shown that CCLOZ treatment $(20 \mathrm{mg} / \mathrm{kg})$ results in selective DB of A10 DA cells (Chiodo and Bunney, 1983; White and Wang, 1983b; Skarsfeldt, 1988, 1994) but leaves unaltered (White and Wang, 1983b; Skarsfeldt, 1988, 1994) or increases (Chiodo and Bunney, 1983, 1985) the number of spontaneously active A9 DA cells. Furthermore, White and Wang (1983b) have shown that doses of APO sufficient to reverse DB in A10 DA cells are ineffective in altering the number of active A9 DA cells. It should be noted, however, that although DA neurotransmission in A10 DA cells is believed to be important for reward (Wise and Rompré, 1989), the degree to which response rates depend on A9 DA cell activity remains to be determined.

In summary, the findings of this second experiment reveal that DB of midbrain DA cells can be observed in awake, freely moving animals, subsequent to chronic antipsychotic drug treatment. Although these findings are consistent with electrophysiological findings in anesthetized (Bunney and Grace, 1978; Chiodo and Bunney, 1983; White and Wang, 1983a,b) and conscious (Bunney and Grace, 1978; Chiodo and Bunney, 1985) animals, they do not support those of Mereu and colleagues (Mereu et al., 1994, 1995; Melis et al., 1998). Last, it is worth noting that only a subgroup of midbrain DA cells go into DB after chronic antipsychotic drug treatment. Recent electrophysiological work has shown that a subgroup of midbrain DA cells are indirectly stimulated by rewarding EBS of the mesencephalic central gray (Moisan and 
Rompré, 1998). The present findings suggest that it is those DA cells that can enter a state of DB that are important for the rewarding effect of the stimulation.

\section{Withdrawal from chronic haloperidol-clozapine}

Withdrawal from CHAL treatment did not produce any enduring change in reward thresholds. Thresholds were back to baseline values within $48 \mathrm{hr}$ after drug withdrawal and remained stable for the next 4 weeks. However, withdrawal from $\mathrm{CHAL}$ resulted in a significant increase in maximal response rates. This effect was present $3 \mathrm{~d}$ after drug withdrawal and disappeared after $\sim 2$ weeks. These findings suggest functional changes selectively in those processes important for motoric capacity.

Withdrawal from CCLOZ treatment did not suggest functional changes in either the neural substrates important for reward or performance. These data contrast findings from a series of EBS studies that used the same dose of clozapine and treatment regimen as those used here. In these earlier studies, CCLOZ treatment caused significant increases in response rates and reductions in current-reset thresholds for stimulation sites in the ventral tegmental area but not the substantia nigra (Seeger and Gardner, 1979; Gardner and Seeger, 1988; Gardner et al., 1993). Delivery of EBS within the area of DA cell bodies in these earlier studies renders it difficult to make direct comparisons between previous and present findings and may in fact constitute the critical variable that accounts for the observed differences.

The findings with CHAL have implications for interpretation of the behavioral restoration in $\mathrm{CHAL}+\mathrm{APO}$-treated rats in experiment 2. First, the behaviorally supersensitive response was initially observed $3 \mathrm{~d}$ after drug withdrawal. This suggests that, although receptor upregulation may in fact have occurred during CHAL treatment, its behavioral consequences may have been masked by the presence of haloperidol, a hypothesis consistent with previous findings (Clow et al., 1980; Rupniak et al., 1984, 1985). More importantly, direct stimulation of postsynaptic receptors by APO would predict a negative correlation between time of resumed responding in $\mathrm{CHAL}+\mathrm{APO}$-treated rats and degree of behavioral supersensitivity. In fact, our data show that those animals that eventually expressed the highest degree of behavioral supersensitivity resumed responding later than those that expressed the lowest (Fig. 12). These findings are not consistent with a significant contribution of supersensitive postsynaptic receptors to the restoration of responding in CHAL+APOtreated rats.

\section{REFERENCES}

Akaoka H, Charléty P, Saunier C-F, Buda M, Chouvet G (1992) Inhibition of nigral dopamine neurons by systemic and local apomorphine: possible contribution of dendritic autoreceptors. Neuroscience 49:879-891.

Barros HMT, Braz S, Carlini EA (1989) Behavioural manifestations elicited by apomorphine, influence of the route of administration. Pharmacology 38:335-340.

Boye SM, Rompré P-P (1996) Effect of pimozide on self-stimulation thresholds under a continuous and fixed-interval schedule of reinforcement. Behav Brain Res 78:243-245.

Bunney BS, Grace AA (1978) Acute and chronic haloperidol treatment: comparison of effects on nigral dopaminergic cell activity. Life Sci 23:1715-1728.

Burt DR, Creese I, Snyder SH (1977) Antischizophrenic drugs: chronic treatment elevates dopamine receptor binding in brain. Science 196:326-328.

Chiodo LA, Bunney BS (1983) Typical and atypical neuroleptics: differ- ential effects of chronic administration on the activity of A9 and A10 midbrain dopaminergic neurons. J Neurosci 3:1607-1619.

Chiodo LA, Bunney BS (1985) Possible mechanisms by which clozapine administration differentially affects the activity of two subpopulations of midbrain dopamine neurons. J Neurosci 5:2539-2544.

Clow A, Theodorou A, Jenner P, Marsden CD (1980) A comparison of striatal and mesolimbic dopamine function in the rat during 6-month trifluoperazine administration. Psychopharmacology 69:227-233.

Doherty MD, Gratton A (1991) Behavioral evidence of depolarization block of mesencephalic dopamine neurons by acute haloperidol in partially 6-hydroxydopamine lesioned rats. Behav Neurosci 105:579-587.

Fouriezos G, Francis S (1992) Apomorphine and electrical selfstimulation of the rat brain. Behav Brain Res 52:73-80.

Freeman AS, Bunney BS (1987) Activity of A9 and A10 dopaminergic neurons in unrestrained rats: further characterization and effects of apomorphine and cholecystokinin. Brain Res 405:46-55.

Gallistel CR, Freyd G (1987) Quantitative determination of the effects of catecholaminergic agonists and antagonists on the rewarding efficacy of brain stimulation. Pharmacol Biochem Behav 26:731-741.

Gallistel CR, Karras D (1984) Pimozide and amphetamine have opposing effects on the reward summation function. Pharmacol Biochem Behav 20:73-77.

Gardner EL, Seeger TF (1988) Anatomically selective action of atypical neuroleptics on the mesocorticolimbic dopamine system. Ann NY Acad Sci 537:502-504.

Gardner EL, Walker LS, Paredes W (1993) Clozapine's functional mesolimbic selectivity is not duplicated by the addition of anticholinergic action to haloperidol: a brain stimulation study in the rat. Psychopharmacology 110:119-124.

Grace AA, Bunney BS (1985) Low doses of apomorphine elicit two opposing influences on dopamine cell electrophysiology. Brain Res 333:285-298.

Grace AA, Bunney BS (1986) Induction of depolarization block in midbrain dopamine neurons by repeated haloperidol: analysis using in vivo intracellular recording. J Pharmacol Exp Ther 238:1092-1100.

Grace AA, Bunney BS, Moore H, Todd CL (1997) Dopamine-cell depolarization block as a model for the therapeutic actions of antipsychotic drugs. Trends Neurosci 20:31-37.

Hollerman JR, Abercrombie ED, Grace AA (1992) Electrophysiological, biochemical, and behavioral studies of acute haloperidol-induced depolarization block of nigral dopamine neurons. Neuroscience 47:589-601.

Melis M, Mereu G, Lilliu V, Quartu M, Diana M, Gessa GL (1998) Haloperidol does not produce dopamine cell depolarization-block in paralyzed, unanesthetized rats. Brain Res 783:127-132.

Melzacka M, Wiszniowska G, Vetulani J (1978) The distribution of apomorphine in rat brain: possible behavioral correlates. Pol J Pharmacol Pharm 30:335-345.

Mereu G, Lilliu V, Vargiu P, Muntoni AL, Diana M, Gessa GL (1994) Failure of chronic haloperidol to induce depolarization inactivation of dopamine neurons in unanesthetized rats. Eur J Pharmacol 264:449-453.

Mereu G, Lilliu V, Vargiu P, Muntoni AL, Diana M, Gessa GL (1995) Depolarization inactivation of dopamine neurons: an artifact? J Neurosci 15: 1144-1149.

Miliaressis E, Rompré P-P, Laviolette P, Philippe L, Coulombe D (1986) The curve-shift paradigm in self-stimulation. Physiol Behav 37:85-91.

Moisan J, Rompré P-P (1998) Electrophysiological evidence that a subset of midbrain dopamine neurons integrate the reward signal induced by electrical stimulation of the posterior mesencephalon. Brain Res 786:143-152.

Nowak JZ, Arbilla S, Galzin AM, Langer SZ (1983) Changes in sensitivity of release modulating dopamine autoreceptors after chronic treatment with haloperidol. J Pharmacol Exp Ther 226:558-564.

Paxinos G, Watson C (1986) The rat brain in stereotaxic coordinates. New York: Academic.

Robertson A, Macdonald C (1986) The effects of some atypical neuroleptics on apomorphine-induced behaviors as a measure of their relative potencies in blocking presynaptic versus postsynaptic receptors. Pharmacol Biochem Behav 24:1639-1643.

Rompré P-P, Wise RA (1989) Behavioral evidence for midbrain dopamine depolarization inactivation. Brain Res 477:152-156.

Rupniak NMJ, Kilpatrick G, Hall MD, Jenner P, Marsden CD (1984) Differential alterations in striatal dopamine receptor sensitivity induced by repeated administration of clinically equivalent doses of 
haloperidol, sulpiride or clozapine in rats. Psychopharmacology 84:512-519.

Rupniak NMJ, Hall MD, Mann S, Fleminger S, Kilpatrick G, Jenner P, Marsden CD (1985) Chronic treatment with clozapine, unlike haloperidol, does not induce changes in striatal D-2 receptor function in the rat. Biochem Pharmacol 34:2755-2763.

Saller CF, Salama AI (1985) Alterations in dopamine metabolism after chronic administration of haloperidol. Possible role of increased autoreceptor sensitivity. Neuropharmacology 24:123-129.

Schotte A, Janssen PFM, Megens AAHP, Leysen JE (1993) Occupancy of central neurotransmitter receptors by risperidone, clozapine and haloperidol, measured ex vivo by quantitative autoradiography. Brain Res 631:191-202.

Seeger TF, Gardner EL (1979) Enhancement of self-stimulation behavior in rats and monkeys after chronic neuroleptic treatment: evidence for mesolimbic supersensitivity. Brain Res 175:49-57.

Skarsfeldt T (1988) Differential effects after repeated treatment with haloperidol, clozapine, thioridazine and tefludazine on SNC and VTA dopamine neurones in rats. Life Sci 42:1037-1044.
Skarsfeldt T (1994) Comparison of short-term administration of sertindole, clozapine and haloperidol on the inactivation of midbrain dopamine neurons in the rat. Eur J Pharmacol 254:291-294.

Skirboll LR, Grace AA, Bunney BS (1979) Dopamine auto- and postsynaptic receptors: electrophysiological evidence for differential sensitivity to dopamine agonists. Science 206:80-82.

Stefanini E, Frau M, Gessa GL (1991) Increase in D2 dopamine receptors in the substantia nigra after chronic (-)-sulpiride treatment. Brain Res 555:340-342.

White FJ, Wang RY (1983a) Comparison of the effects of chronic haloperidol treatment on A9 and A10 dopamine neurons in the rat. Life Sci 32:983-993.

White FJ, Wang RY (1983b) Differential effects of classical and atypical antipsychotic drugs on A9 and A10 dopamine neurons. Science 221:1054-1057.

Wise RA (1996) Addictive drugs and brain stimulation reward. Ann Rev Neurosci 19:319-340.

Wise RA, Rompré P-P (1989) Brain dopamine and reward. Ann Rev Psychol 40:191-225. 